\title{
Developing an Oral Presentation Assessment to the Teacher Education Program Student
}

\author{
Nuansa Bayu Segara ${ }^{1}$, Enceng Yana $^{1} \&$ Yopi Nisa Febianti ${ }^{1}$ \\ ${ }^{1}$ Universitas Swadaya Gunung Djati, Cirebon, Indonesia \\ Correspondence: Nuansa Bayu Segara, Universitas Swadaya Gunung Djati, Cirebon, Indonesia. E-mail: \\ nuansasegara88@gmail.com
}

Received: May 14, 2018; Accepted: May 28, 2018; Published: June 27, 2018

\begin{abstract}
Performance evaluation of an oral presentation in the lecture process should be valid and accountable to avoid subjectivity and bias on the assessment. Based on ADDIE models, the researcher makes an oral presentation instrument for peer assessment, developed, implemented and tested statistically. Teacher candidates participate directly in the evaluation process based on the oral presentation rubric. The rubric became a guide for students in determining the criteria and performance measurement scale oral presentation of his colleagues. Statistical tests performed with Second Order Confirmatory Factor Analysis (CFA) Order using the Smart PLS 3.0. This instrument was built based on three dimensions of oral presentation: content, delivery, and collaboration. As a result, all three of it were found to be statistically valid and reliable, meeting the criteria so that it can be used for peer assessment of oral presentation.
\end{abstract}

Keywords: oral presentation, peer assessment, rubric, CFA

\section{Introduction}

The oral presentation is one of the skills needed by people in this century. It is a part of the communication skills which includes in the 21st Century Skills (see Trilling and Fadel, 2009). As teacher candidates, students of education faculty are required to have excellent communication skill. It will help them to compete in the importunity of higher teaching quality. Based on the observations during lectures, first-year students in the teacher education program have low oral presentation skills, so there is a need of consistent improvement of those skills. One way to do this is to use peer assessment in the evaluation process of oral presentation (Aryadoust, 2015; Sundrarajun \& Kiely, 2010; Suñol \& Arbat, et al., 2015).

This article describes the research process aiming to construct an oral presentation assessment instrument. Empirically, the use of alternative assessment through peer assessment conducted in universities can cause a positive impact on students (Bhati, 2012; Grez, Valcke and Berings 2010; Nortcliffe, 2012). Through this alternative assessment, students will understand the criteria that must be achieved to obtain the better values in oral presentation. They will actively participate in lecturing process, and it is possible for lecturers to make changes in teaching learning process to improve the quality of the course, because in each assessment process they will receive and give feedback both reflectively and constructively (Thomas, Martin and Pleasants, 2011). In fact, the use of alternative assessment instrument can be either as formative assessment or as summative assessment when it is conducted in careful and cautious consideration (White, 2009).

Oral presentation assessment is very crucial in lecturing process. Joughin (2010) reveals seven advantages of doing an assessment in oral presentation, they are: 1) The learning outcomes demand it;2) It allows probing of the students' knowledge; 3) It reflects the world of practice; 4) It improves learning; 5) It suits some students; 6) The meaning of questions can be clarified; 7) It helps to ensure academic integrity. Those advantages can extend when the processes were carried out through each assessment. A numerous motivation will be gained by students when they conduct peer assessment technique. However, assessing and being assessed by their classmates certainly bring about a high tension among students. Thus, teachers need to provide a well-designed rubric since the scoring criteria and levels existing within the rubric will ease the students to compare and to determine the standard of performance of their classmates.

In this study, the instruments of oral presentation assessment are completed by a rubric. The students use it to rate and compare their classmates' presentation performance by following the description guideline in the rubric. Those criterions and levels were designed based on certain dimensions and indicators. The criterions in rubric were 
constructed by identifying the lowest and the highest quality of performance (Moskal, 2000), that standard becomes the scoring basic of oral presentation performance. The functions of rubric is not only as a document used for determining the criteria, scale, and scoring in assessment process, but also as an evidence which represents constructs of evaluation (Jeon, 2015), these are considered necessary to maintain accountability ratings.

There are several advantages of using the rubric in the classroom, they are: 1) the rubric is very useful and helps students to perform tasks; 2) students are able to know and understand the teachers' expectations related to performance assessed; 3) The rubric has contributed to improve the skills assigned (Reynolds-Keefer, 2010). The rubric is very flexible to be implemented in the learning process. It is applied in the process of assignment, designing products, and performance skills of the students (see Tierney \& Simon, 2004). It is very relevant when the rubric implementation in the learning process has innovative values and has a chance to develop its function and benefits.

Due to many advantages of using rubric in performance assessment, this study intends to develop the instrument of assessment for oral presentation based rubric. This study was importantly conducted to increase accountability and transparency of assessment in teaching learning process. The result of this study is expected to complete the traditional assessment process. Oral presentation is a skill which should be mastered by teachers candidate, through this alternative assessment, the will know the dimensions and indicators of an ideal oral presentation performance. By identifying those criteria, there will be some feedback from teachers candidate to improve their oral presentation during their learning.

This research attempted to answer how the validity and reliability of peer assessment instruments for an oral presentation are. The dimensions of the oral presentation was designed based on the structure proposed by Grez, Valcke and Berings (2010) which use some contextual adaptations. They use two-dimensional "content" and "delivery" consisting of 10 items. On this research, it was added one dimension, "collaboration", because of the importance of a skill to answer questions from the audience and the importance of having the attention and cooperation of fellow group members.

\section{Method}

The study aimed at developing an oral presentation instrument which was conducted by using peer assessment approach. ADDIE Model is fit to be implemented in a study which was oriented to produce an instructional product (Nadiyah \& Faaziah, 2015). In addition, it is also suitable to construct an assessment product. ADDIE Model is in line with the objective of the study that is to develop an assessment product. Based on the procedures of ADDIE Model, the oral presentation instruments which were designed will go through research and development process. This step theoretically is adequate to develop a product which is related to instructional development. There are five stages in this model, they are: Analysis, Design, Development, Implementation, and Evaluation.

In the Analysis phase, this research began to identify weaknesses and needs of students in conducting oral presentation. Then deciding the assessment approach which is used to scoring students' oral presentation. Design phase is conducted to define, determine the dimensions and indicators in oral presentation. The dimensions of oral presentation consist of content, delivery, and collaboration. Those aspects were chosen based on the students' needs found in Analysis phase. In the development phase, a researcher conducted content validation by asking experts deliberation. The development was conducted after revising instrument based on what was recommended by experts. Implementation phase is a process of instrument try out which has been through the design and development stage. The try out was conducted over seven weeks on second grade which consists of 49 people in one class. The evaluation phase is carried out in each step of the study and focus on the statistical evidence to determine the validity and reliability of assessment instruments.

\subsection{Data Collection}

The data were gathered in seven weeks. There are 49 education faculty students which were divided into 10 groups. Each group consists of 4-5 members in which they will present their report study in 15 minutes. During group presentation, there were 44 students who play a role as raters to asses their classmates' oral presentation. The rubric is used to look at the criteria and scale of measurement, so there will be no hesitations to evaluate the performance of their classmate's presentation.

The data collection conducted over seven weeks. After numbering the students from $1-49$, they were divided into ten groups. Each group of 4-5 people, each member of the group individually will present the research report with an oral presentation at the duration of 15 minutes. A total of 44 other students will act as assessors who assess the oral presentation. The rubric is used to look at the criteria and scale of measurement, so not allow any hesitations to evaluate the performance of their classmate's presentation itself. Supposedly, at each meeting, there will be 4-5 
presenters who performed and judged by 44 reviewers, so that the data collected is 220 .The process of data collection did by as much as ten times the meetings, so the total data collected should have as many as 2200 . But not every meeting of the audience present in full, so that total of 2000 data collected, the amount was less than expected but very useful for statistical testing.

\subsection{Data Analysis}

Test of validity and reliability statistically become the main focus in this study. The construct of oral presentation was built by adopting from some previous research, then in line with students of teacher candidate's need. Based on theoretical considerations, the writer used PLS ( Partial Least Square) to measure validity and reliability by CFA second order technique. The requirements that should be met for a valid instrument of oral presentation are having a high factor loading factors (>0.7) and average variance extracted (AVE) (>0.5) and having composite reliability (Dillon-Goldstein's rho) with a score more than 0.70 (Ghazali, 2015; Ravand \& Baghaei, 2016).

\subsection{Design and Development of Instruments}

The results from the analysis of need assessment can be sum up as follows: First, it needs an external motivation which can motivate students to conduct oral presentation well. Second, students need criteria or the way to conduct an oral presentation well. Third, students need feedback and developing critics after conducting oral presentation. Based on the analysis above, the result shows that there is a need to have objective, accountable, valid and reliable assessment to rate the students' oral presentation. Therefore, peer assessment was chosen as to score students' oral presentation to group motivation and accommodate the best performance. Some factors that can be done to prepare an assessment of oral presentation, they are: 1) Determine the dimension which can be measured; 2) Determine the indicators which are in line with the dimension; 3) Design some criteria in a rubric which are useful to ease a scoring activity; 4) Determine the assessment format of instrument which is easily understood and used; 5) Determine competence level in oral presentation.

Designing phase was conducted to determine oral presentation. After analyzing and comparing the results of previous studies, it was decided that this study would use three dimensions and ten indicators in assessing student's oral presentation. The first dimension is Content which has three indicators; content mastery, focus and effectivity, and creativity. The second dimension is Delivery which has five indicators, they are: eye contact and gesture, communicative, volume, enthusiastic, and formal language used. The next dimension is Collaboration which consist of two indicators, they are answering the questions and cooperative. Dimensions and indicators included in instrument were conformed to students' need and students' environment.

The next phase is the development of assessment instrument. After the instrument had been prepared well, the researcher would carry on Judgment Validation by choosing some experts. The assessment of instrument was judged by a professor from Indonesian Education University Bandung whose expertise in measurement and evaluation. The expert recommended to administer content validity of dimension, indicators, and items steps which were stated in the instrument of oral presentation (those steps previously did not state in the paper). The following is a table of some components in content validity of oral presentation:

Table 1. Content Validity of Oral Presentation Assessment

\begin{tabular}{lll}
\hline Dimension & Indicator & Item \\
\cline { 2 - 3 } Content & Content Mastery & Having an understanding and developing a topic being presented \\
\cline { 2 - 3 } & Effectiveness and Focus & Effective and focus on delivering the topic during the presentation \\
\hline \multirow{2}{*}{ Celivery } & Eye Contact and Gesture & $\begin{array}{l}\text { Deliver the material in interesting way and show supporting media of } \\
\text { presentation }\end{array}$ \\
\cline { 2 - 3 } & Communicative & Speak clearly and able to be understood by the audience. \\
\cline { 2 - 3 } & Volume & Having a proper volume of voice that can be heard by the entire audience. \\
\cline { 2 - 3 } & Enthusiasm & Shows the excited expressions and body language. \\
\cline { 2 - 3 } & Formal Language & Using a formal Indonesian Language during presentation \\
\hline Collaboration & Answering Questions & Answering questions from the audience confidently and accurately. \\
\cline { 2 - 3 } & Group Collaboration & Having attention and cooperation with group members \\
\hline
\end{tabular}

Source: Mandel (2008); De Grez, Valcke \& Berings (2010); rubistar.com 


\section{Results}

After viewing and analyzing the content validity, item description, and instrument format being used in measuring the quality of the oral presentation, the expert said that the instrument can be implemented directly, then it should statistically be tested for validity and reliability (content validity and composite reliability). Before the implementation, the researcher made an oral presentation criteria which consist of four levels and ten indicators. The following table shows the criteria of the four levels of oral presentation skills (Appendix B).

\subsection{Validity}

Furthermore, the instrument of assessment which had been validated by expert implemented in the lecture. Students who did presentations were assessed by lecturer and other students who were present. After seven meetings, it generate 2000 data which would be tested in validity and reliability using the statistical approach SmartPLS 3.0 which applied Second Order CFA (Confirmatory Factor Analysis). Here are the results:

Table 2. The Value of Average Variance Extracted

\begin{tabular}{llll}
\hline & $A V E$ & $s e$ & $t$ \\
\hline Collaboration & 0,747 & 0,010 & 73,428 \\
Content & 0,687 & 0,008 & 81,880 \\
Delivery & 0,567 & 0,009 & 59,790 \\
\hline
\end{tabular}

As a result, the Instrument Performance Assessment Oral Presentations had been regarded as statistically Valid and Reliable, because ten indicators of the three-dimensional measurement have a value of loading factor of $>0.7$ and the value AVE (average variance extracted)> 0.5. Ravand and Baghaei, (2016) stated that AVE is the mean of communalities (i.e., factor loadings squared, the which should be at least 0.50 ) of the indicators associated with any given construct. AVEs of 0.50 indicate that the construct explains at least half of the variance of its observed variables.

Table 3. Factor Loading, Standard Error, and Bootstrap

\begin{tabular}{lcll}
\hline & $\boldsymbol{\lambda}$ & $s e$ & $t$ \\
\hline $\mathrm{C} 1$ & 0,856 & 0,006 & 149,480 \\
$\mathrm{C} 2$ & 0,855 & 0,006 & 150,292 \\
$\mathrm{C} 3$ & 0,773 & 0,010 & 74,761 \\
$\mathrm{CO} 1$ & 0,894 & 0,005 & 187,607 \\
$\mathrm{CO} 2$ & 0,834 & 0,010 & 80,243 \\
D1 & 0,753 & 0,010 & 72,559 \\
D2 & 0,786 & 0,009 & 83,011 \\
D3 & 0,753 & 0,010 & 74,635 \\
D4 & 0,761 & 0,010 & 73,071 \\
D5 & 0,710 & 0,015 & 47,687 \\
\hline
\end{tabular}

To find out the significance of the first order constructs, the researcher conducted bootstrapping. Based on an external loading, it can be stated that all indicators are having construct validity with T-Statistic value > 1.96. That means all constructs of the first order are constructs dimensions, forming the oral presentation constructs.

\subsection{Reliability}

Reliability test of oral presentation instruments can be measured from the value of Dillon-Goldstein's rho. Cronbach's alpha value in PLS underestimate compared with Dillon-Goldstein's rho, so it should see the value of composite reliability (Ghazali, 2015; Ravand and Baghaei, 2016). Here are the results,

Table 4. The Value of Composite Reliability, Standard Error, and Bootstrap

\begin{tabular}{lccc}
\hline & rho & se & $t$ \\
\hline Collaboration & 0,855 & 0,007 & 127,437 \\
Content & 0,868 & 0,005 & 192,338 \\
Delivery & 0,867 & 0,004 & 194,280 \\
\hline
\end{tabular}


The instrument also has sufficient reliability to meet the criteria for a composite measurement model with reliability $>0.7$. The amount of all three dimensions is as follow. Dimensional Content is 0.868 , Delivery dimension is 0.867 , and the dimensions of Collaboration is 0.855 . Based on the test results above, it can be stated that all of the aspects that make up the oral presentation construct are reliable.

\subsection{The Final Product}

The aim of this study is to design an instrument of oral presentation assessment through pair assessment. The product consists of an assessment instrument and a rubric of criteria description (Appendix B) which was designed by using the procedures of ADDIE model following the criteria of validity and reliability tests.

\section{A Valid and Realibility Instrument of Oral Presentation Assessment}

\begin{tabular}{|c|c|c|c|c|c|c|c|c|c|}
\hline \multirow{2}{*}{\multicolumn{10}{|c|}{$\begin{array}{l}\text { Group : } \\
\text { Report Title : }\end{array}$}} \\
\hline & & & & & & & & & \\
\hline \multirow{4}{*}{ No } & \multirow{4}{*}{ Items } & \multicolumn{8}{|c|}{ Name of Group Member } \\
\hline & & \multicolumn{4}{|c|}{ a: } & \multicolumn{4}{|c|}{ b: } \\
\hline & & \multicolumn{8}{|c|}{ Scoring } \\
\hline & & 1 & 2 & 3 & 4 & 1 & 2 & 3 & 4 \\
\hline 1 & Having an understanding and developing the topic delivered. & & & & & & & & \\
\hline 2 & Focused and effective in delivering topic during presentation & & & & & & & & \\
\hline 3 & $\begin{array}{l}\text { Delivering the materials interactively and using a media to support } \\
\text { presentation }\end{array}$ & & & & & & & & \\
\hline 4 & Having an eye contact and confidence during presentation. & & & & & & & & \\
\hline 5 & Speak clearly so that it can be understood by the audiences & & & & & & & & \\
\hline 6 & $\begin{array}{l}\text { Having an appropriate and consistence volume of sound listened by the } \\
\text { audience during the presentation }\end{array}$ & & & & & & & & \\
\hline 7 & Showing expressive gestures & & & & & & & & \\
\hline 8 & Using well-structured Indonesian Language during presentation & & & & & & & & \\
\hline 9 & Answering questions from audiences accurately and surely & & & & & & & & \\
\hline 10 & Having good attention and cooperation among group members & & & & & & & & \\
\hline \multicolumn{2}{|r|}{ Score } & & & & & & & & \\
\hline \multicolumn{2}{|c|}{ Total } & & & & & & & & \\
\hline
\end{tabular}

Figure 1. A Valid and Reliable Instrument of Oral Presentation Assessment

Source: Research Results 2016

Besides the instrument, the author also used other components, namely: 1) the identity of assessors; 2) copies of the oral presentations assessment instruments, and 3) a description of the criteria and criteria level. Oral presentation evaluation sheets filled in by peer students based on the presenter's performance during the presentation. The Instructor was always trying to remind students to be objective and do not see the other factor not included in rubric because Nortcliffe (2012) states when he used peer assessment for five years, he got some of problems related to race difference, conflicts among students which can influence the objectivity of assessment. In the process of this study the authors also found the same case. The existence of conflicts among students has an impact on the question-statement and responses to be sarcastic. There is a need for giving instruction and clarification when discussion atmosphere is getting chaos because when the teacher ignored it then the discussion will go out of the content.

During the lecture by using alternative assessment in each student presentations, there are still some obstacles either technical or procedural problems in assessment. Therefore, the students were asked to provide some feedback about the quality of oral presentation assessment instruments. A questionnaire that has been used was designed by the semantic differential technique with six choices. Here is the result of a student's perspective on the use of the instrument. 


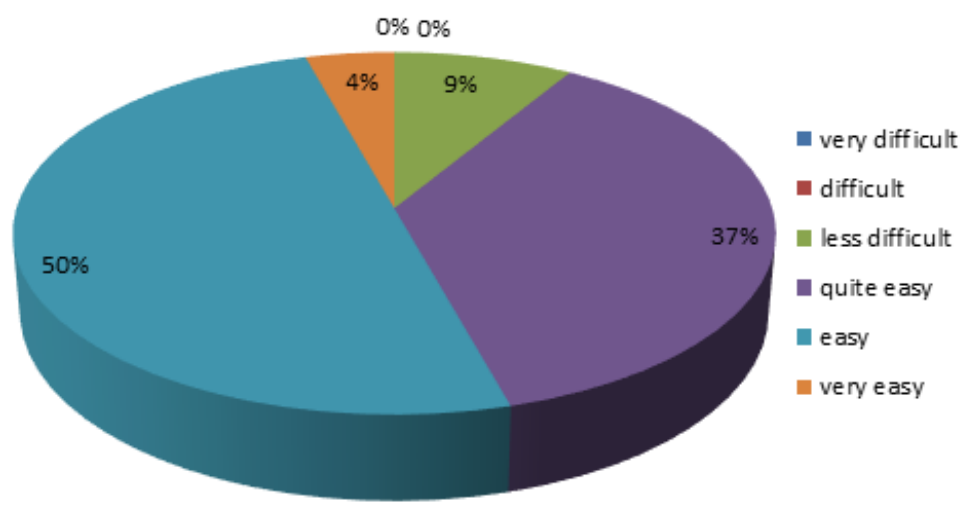

Figure 2. Students' Difficulty in Using Instrument

This assessment instrument are designed as practical as possible, so that Instructor can be easily used it due to the effectiveness of lecturing time. When a question about the degree of difficulty in completing the evaluation instruments was given to the students, only a few of students felt difficult to fill in the instrument of oral presentation assessment. Half of the students who participated in filling the instrument felt easily to perform the evaluation process. A few of students felt that using the instrument were very easy, and none of the students felt very difficult and faced difficulties to assess the oral presentation with these tools. If the score of student responses is being accumulated to the maximal value score, then the level of easiness in using the instrument is around $75 \%$ which means that the instruments has a high standard of convenience category.

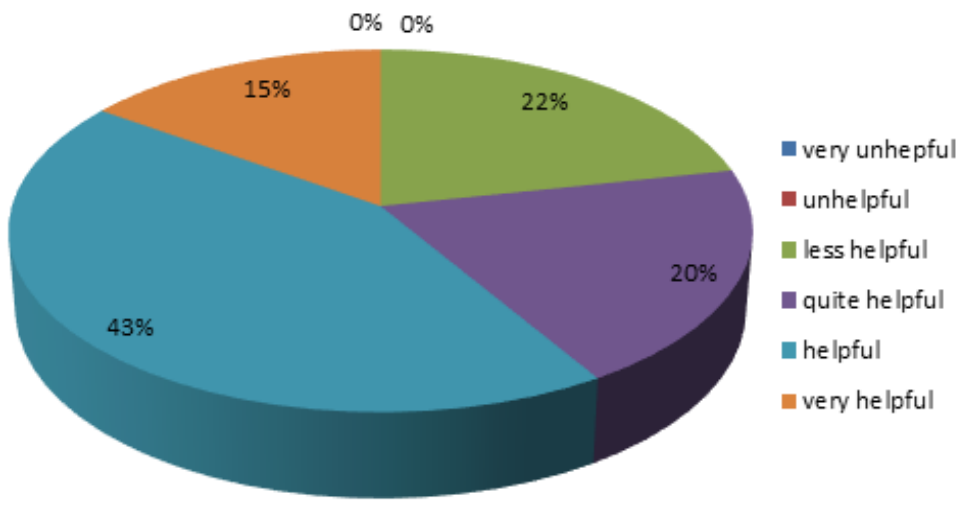

Figure 3. The existence of the Rubric in Assessment

The rubric in this assessment was designed to help students see the suitability of their presentations with four performance criteria described. In research conducted by Grez, Valcke and Berings (2010), it was found that students felt difficult to assess the sub variable content compared to delivery. To anticipate the previous problem, the instrument of students' assessment in this study was completed by some description of oral presentation criteria in form of scoring rubric. As a result, the students' responses towards the presence of assessment rubric were relatively positive. Nearly half of the students felt that rubric was enough to help assist them in the evaluation process and less than half of students felt that the rubric was less helpful them in the evaluation process. It happened because they thought that the items contained in the instruments were very clear. Furthermore, a few of students considered that the use of the rubric in assessing other students was very helpful. Students were often feeling in doubt in assessing their classmates during presentation, so that the rubric truly eases the use of instrument. Besides that, rubric also provided expectations, criteria, and attributes to be evaluated, so that they can understand the reflective shortcomings when it will be, and after the presentation (see Oberg, 2010). After the calculated overall, the level of assistance the assessment rubric is approximately $75 \%$, which means a high level of its support. 


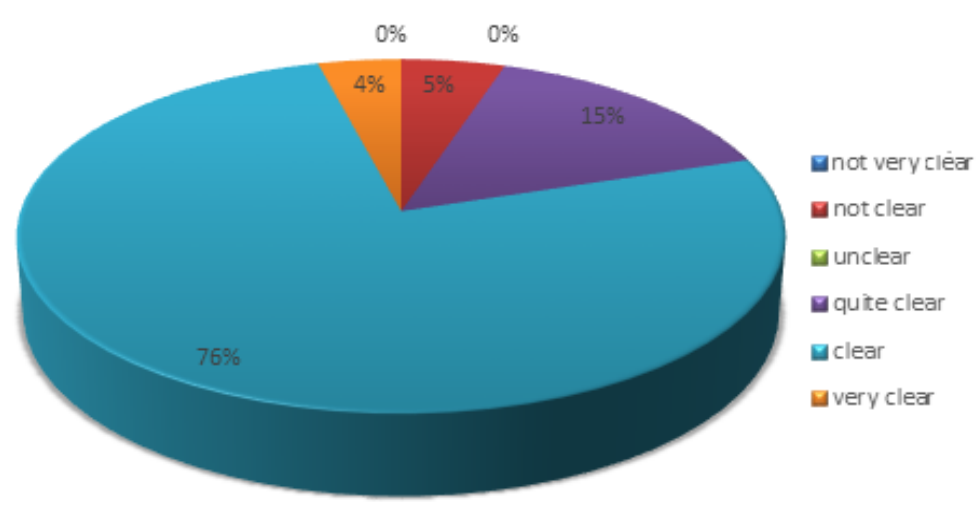

Figure 4. A Clarity of Criteria Description on Rubric

In an assessment rubric, the criteria should ideally have a clear description, so it can distinguish each level of ability in the oral presentation. The rubric in this study was designed using four levels. Students need to understand how to apply the description of these criteria during the assessment. The diagram above is a picture of clarity in the rules description rubric used by the student. The result clearly shows positive response. Most of students considered that a description of the existing criteria on the rubric is clear and capable of distinguishing criteria for oral presentation of each level. A small portion of students considered that explanation is very clear; another fraction was not obvious and quite clear. Overall, the level of clarity of the description of the criteria on the rubric is $79 \%$ which means it have a high degree of clarity.

\section{Conclusion}

Oral presentations instrument in this research has been passing through a series process of the measurement tool development. It started from analysis, design, development, implementation, and evaluation. Statistically, it can be concluded that the oral presentation instrument through peer-assessment has valid and reliable criteria. The instrument also has an excellent range, and the current rubric in the package also has good clarity and able to help students in comparing the performance of his colleagues with a description of the criteria and the performance level of the oral presentation.

\section{References}

Aryadoust, V. (2015). Self and Peer Assessments of Oral Presentations by First-Year University Students. Educational Assessment,20(3), 199-225. https://doi.org/10.1080/10627197.2015.1061989

Ghozali, I., \& Latan, H. (2015). Partial Least Squares: Konsep, Teknik dan Aplikasi Menggunakan Program SMART PLS 3.0 Untuk Penelitian Empiris. Badan Penerbit Universitas Diponegoro: Semarang.

Grez, D., Luc, Valcke, \& Beringa (2010). Peer assessment of oral presentation skills. Procedia - Social and Behavioral Sciences, 2(2), 1776-1780. https://doi.org/10.1016/j.sbspro.2010.03.983

Jeong, H. (2015). What is your teacher rubric? Extracting teachers' assessment constructs. Practical Assessment, Research \& Evaluation, 20(6), 2.

Joughin, G. (2010). A short guide to oral assessment. Leeds Met Press.

Mandel, S. (2010). Effective Presentation Skills: A Practical Guide for Better Speaking. Crisp Publications.

Moskal, B. M. (2000). Scoring rubrics: what, when and how? Practical Assessment, Research \& Evaluation, 7(3).

Nadiyah, R. S., \& Faaizah, S. (2015). The Development of Online Project-Based Collaborative Learning using ADDIE Model. Procedia-Social and Behavioral Sciences, 195, 1803-1812. https://doi.org/10.1016/j.sbspro.2015.06.392

Northcliffe, A. (2012). Can students assess themselves and their peers?: A five-year study. Student Engagement and Experience Journal, 1(2). https://doi.org/10.7190/seej.v1i2.29

Oberg, C. (2010). Guiding classroom instruction through performance assessment. Journal of Case Studies in Accreditation and Assessment, 1(1).

Ravand, H., \& Baghaei, P. (2016). Partial Least Squares Structural Equation Modeling with R. Practical Assessment, Research \& Evaluation, 21(11), 2. 
Reynolds-Keefer, L. (2010). Rubric-referenced assessment in teacher preparation: An opportunity to learn by using. Practical Assessment, Research \& Evaluation, 15(8).

Sundrarajun, C., \& Kiely, R. (2010) The oral presentation as a context for learning and assessment, Innovation in Language Learning and Teaching, 4(2), 101-117. https://doi.org/10.1080/17501220903125021

Suñol, J. J., Arbat, G., Pujol, J., Feliu, L., Fraguell, R. M., \& Planas-Lladó, A. (2015). Peer and self-assessment applied to oral presentations from a multidisciplinary perspective. Assessment \& Evaluation in Higher Education,41(4), 622-637. https://doi.org/10.1080/02602938.2015.1037720

Suñol, J. J., Arbat, G., Pujol, J., Feliu, L., Fraguell, R. M., \& Planas-Lladó, A. (2016). Peer and self-assessment applied to oral presentations from a multidisciplinary perspective. Assessment \& Evaluation in Higher Education, 41(4), 622-637. https://doi.org/10.1080/02602938.2015.1037720

Thomas, G., Martin, D., \& Pleasants, K. (2011). Using self and peer-assessment to enhance students' future learning in higher education. Journal of University Teaching \& Learning Practice, 8(1), 5.

Tierney, R., \& Simon, M. (2004). What's still wrong with rubrics: focusing on the consistency of performance criteria across scale levels. Practical Assessment, Research \& Evaluation, 9(2), 1-10.

Trilling, B., \& Fadel, C. (2009). 21st Century Skills: Learning for Life in Our Times. Jossey-Bass.

Van Ginkel, S., Gulikers, J., Biemans, H., \& Mulder, M. (2015). The impact of the feedback source on developing oral presentation competence. Studies in Higher Education, 1-15.

White, E. (2009). Student perspectives of peer assessment for learning in a public speaking course. Asian EFL Journal, 33(1), 1-36.

\section{Copyrights}

Copyright for this article is retained by the author(s), with first publication rights granted to the journal.

This is an open-access article distributed under the terms and conditions of the Creative Commons Attribution license (http://creativecommons.org/licenses/by/4.0/). 